\title{
TINGKAT KETERBACAAN WACANA BUKU TEKS PELAJARAN BAHASA DAN SASTRA INDONESIA KELAS VII DENGAN CLOZE TEST PADA SISWA SMPN 3 TAROWANG KAB. JENEPONTO
}

\author{
Rinawati Bahdar \\ SMP Negeri Tarowang, Kabupaten Jeneponto \\ rinawati_bahar@gmail.co.id.
}

\begin{abstract}
This study aimed to describe the level of legibility Discourse Textbooks Indonesian Language and Literature at the Class VII Students SMP 3 Tarowang Kab. Jeneponto with Cloze Test. This research used descriptive qualitative method. The population in this study were all discourses were eligible to be tested by using Cloze Test. The textbook is a textbook study Indonesian were Language and Literature 1 SMP / MTs were prepared by Suparno, et al and published by Earth Literacy. In the textbook discourse that can serve the population consists of 11 discourses of fiction and 9 discourses of nonfiction. The population sampled only $50 \%$ of the total discourses. Thus, the amount of which have analyzed discourse discourse as much as 5 fiction and 5 nonfiction discourse. The discourse selected randomly and tested to class VII SMPN 3 Tarowang with Cloze Test. Data collection technique were observation and tests. The discourse samples were selected to be analyzed in two ways : (1) the analysis of any discourse and ( 2 ) the analysis of the data overall discourse. The conclusions drawn from the results of the analysis to determine whether the position of the reader in the position of independent reading level / free, instructional / moderate, or frustrated/failed. Based on the findings that ( 1 ) readability level of discourse analysis I, II, III, VI , VII , IX, and X can be used as teaching material for students of class VII SMPN 3 Tarowang based Cloze Test. The discourse was at instructional reading level, which means that discourse has a moderate level of difficulty and can be understood by the student, (2) analysis of discourse readability level IV,$V$, and VIII were not feasible for students of class VII SMP 3 Tarowang. This discourse put the respondent at the level of reading frustrating and difficult to understand by students. This discourse would make a general reading materials, (3) percentage of overall readability level discourse suggests that legibility was due to be at the instructional reading level. This means reading level textbooks Indonesian Language and Literature 1 SMP / MTs were prepared by Suparno, et al as a whole can be understood by students and fit for use as teaching materials in SMPN 3 Tarowang.
\end{abstract}

Key Words: Cloze Test, reading, teks book.

\section{Abstrak}

Penelitian ini bertujuan mendeskripsikan tingkat keterbacaan Wacana Buku Teks Pelajaran Bahasa dan Sastra Indonesia Kelas VII pada Siswa SMPN 3 Tarowang Kab. Jeneponto dengan Cloze Test. Penelitian ini menggunakan metode deskriptif kualitatif. Populasi dalam penelitian ini adalah semua wacana yang memenuhi syarat untuk diuji dengan menggunakan Cloze Test. Buku teks yang diteliti adalah buku teks Bahasa dan Sastra Indonesia 1 
SMP/MTs yang disusun oleh Suparno, dkk dan diterbitkan oleh Bumi Aksara. Dalam buku teks tersebut wacana yang dapat dijadikan populasi terdiri atas 11 wacana fiksi dan 9 wacana nonfiksi. Populasi yang dijadikan sampel hanya 50\% dari jumlah wacana. Jadi, jumlah wacana yang akan dianalisis sebanyak 5 wacana fiksi dan 5 wacana nonfiksi. Wacana tersebut dipilih secara acak dan akan diteskan kepada siswa kelas VII SMPN 3 Tarowang dengan Cloze Test. Teknik pengumpulan datanya adalah observasi dan tes. Wacana yang terpilih menjadi sampel dianalisis dengan dua cara yaitu: (1) analisis setiap wacana dan (2) analisis keseluruhan data wacana. Dari hasil analisis ditarik kesimpulan untuk menentukan posisi pembaca apakah di posisi tingkat baca independen/bebas, instruksional/sedang, atau frustasi/gagal. Berdasarkan hasil penelitian bahwa (1) Analisis tingkat keterbacaan wacana I, II, III, VI, VII, IX, dan X dapat dijadikan bahan ajar untuk siswa kelas VII SMPN 3 tarowang berdasarkan Cloze Test. Wacana tersebut berada pada tingkat baca intruksional yang berarti wacana tersebut memiliki tingkat kesulitan yang sedang dan dapat dipahami oleh siswa; (2) Analisis tingkat keterbacaan wacana IV, V, dan VIII tidak layak bagi siswa kelas VII SMPN 3 Tarowang. Wacana ini menempatkan responden pada tingkat baca frustasi dan sulit dipahami oleh siswa. Wacana ini cocok dijadikan bahan bacaan umum; (3) Persentase secara keseluruhan tingkat keterbacaan wacana menunjukkan bahwa keterbacaan wacana sedang karena berada pada tingkat baca instruksional. Hal ini berarti tingkat keterbacaan buku teks Bahasa dan Sastra Indonesia 1 SMP/MTs yang disusun oleh Suparno, dkk secara keseluruhan dapat dipahami oleh siswa dan layak digunakan sebagai bahan ajar di SMPN 3 Tarowang.

Kata Kunci: Cloze Test, Keterbacaan, Buku Tesk.

\section{PENDAHULUAN}

Salah satu faktor penentu keberhasilan pembelajaran bahasa Indonesia di sekolah adalah buku teks atau buku pelajaran yang digunakan sebagai penunjang pembelajaran. Buku teks adalah buku yang dijadikan pegangan siswa sebagai sumber belajar. Buku teks yang dijadikan pegangan oleh siswa dalam pembelajaran harus sesuai dengan kurikulum pendidikan nasional dan berfungsi mendukung terbentuknya kompetensi lulusan siswa.

Hasil studi yang telah dilakukan oleh beberapa peneliti menunjukkan bahwa buku teks sangat berperan dalam meningkatkan prestasi belajar siswa. Buku teks harus memenuhi standar mutu agar keberadaan buku teks yang digunakan di sekolah dapat efektif menunjang pencapaian kompetensi dan bermakna terhadap prestasi belajar. Perlu adanya pengendalian mutu yang berkaitan dengan isi, bahasa dan keterbacaan, penyajian, dan kegrafikan buku teks pelajaran yang diterbitkan. Pengendalian mutu buku teks secara teknis dilaksanakan oleh Pusat Perbukuan Departemen Pendidikan Nasional di bawah wewenang Badan Standar Nasional Pendidikan (BSNP).

Berdasarkan kriteria dalam menentukan standar buku teks pelajaran maka penulis terdorong untuk melakukan penelitian dan mengkaji keterbacaan wacana. Selain itu, penulis memilih untuk meneliti masalah keterbacaan dengan tujuan 
untuk menguji bahwa wacana dalam buku teks pelajaran sekolah sudah dibuat dengan tepat atau belum. Penelitian ini dibatasi hanya pada buku teks yang dipakai di kelas VII SMP Negeri 3 Tarowang pada mata pelajaran bahasa Indonesia. Buku teks yang menjadi pegangan siswa ini disusun oleh Suparno dkk yang diterbitkan pertama kali pada tahun 2008 oleh Bumi Aksara. Keterbacaan ini akan dianalisis dengan Cloze Test.

Penelitian yang relevan dilakukan oleh Basri (2011) dengan judul "Keterbacaan Buku Teks Pelajaran Bahasa Indonesia Kelas IX SMP Karangan Nurhadi, dkk". Hasil penelitian yang dilakukan oleh Basri menunjukkan bahwa wacana yang ada dalam buku karangan Nurhadi, dkk yang diterbitkan oleh Erlangga secara umum tingkat keterbacaannya sangat rendah. Wacananya sukar dipahami oleh siswa dan belum layak untuk dijadikan bahan ajar di Kec. Rilau Ale Kab. Bulukumba.

Bertolak dari beberapa penelitian tentang keterbacaan buku teks tersebut, maka penulis mengambil lokasi penelitian di SMPN 3 Tarowang yang letaknya di daerah pedesaan, serta penerbit buku dan penulis yang berbeda dengan buku sebelumnya. Jumlah buku mata pelajaran bahasa Indonesia di kelas VII SMP Negeri 3 Tarowang saat ini hanya 1 (satu). Selebihnya adalah Lembar kerja Siswa (LKS).

\section{TINJAUAN PUSTAKA}

\section{A. Wacana}

\section{Pengertian Wacana}

Secara etimologis wacana berasal dari bahasa Sansekerta, yaitu vecana yang berarti bacaan. Dalam bahasa Jawa Kuno kata vecana berarti "bicara, kata, ucapan". Kata tersebut kemudian diserap ke dalam bahasa Indonesia yang berarti ucapan, percakapan. Wacana diartikan secara sederhana oleh Purwadarminta (dalam Saemina, 2005) sebagai ucapan, percakapan, dan kuliah.

Tarigan (Darma, 2009:2) mengemukakan bahwa wacana adalah satuan bahasa yang terlengkap dan tertinggi atau terbesar di atas kalimat atau klausa dengan koherensi dan kohesi yang tinggi yang berkesinambungan, yang mempunyai awal dan akhir yang nyata, disampaikan secara lisan atau tertulis. Pemahaman ini membawa kita pada wacana yang kohesif dan koheren. Kohesi merupakan keserasian hubungan unsur-unsur dalam wacana, sedangkan koheren merupakan kepaduan wacana sehingga komunikatif dan mengandung satu ide.

\section{Ciri dan Sifat Wacana}

Berdasarkan pengertian wacana, Syamsuddin dkk. (1998), menjelaskan ciri dan sifat wacana sebagai berikut:

a. Wacana dapat berupa rangkaian ujar secara lisan atau tulisan atau rangkaian tindak tutur;

b. Wacana mengungapkan suatu hal (subjek);

c. Penyampaiannya teratur, sistematis, koheren, lengkap dengan semua situasi pendukungnya;

d. Wacana memiliki satu kesatuan misi dalam rangkaian itu;

e. Wacana dibentuk oleh unsur segmental dan nonsegmental. 


\section{Wujud dan Jenis Wacana}

a. Segi Realitas

b. Media Komunikasi

c. Penyusunan

Ditinjau dari segi penyusunan, isi dan sifatnya, wacana itu banyak jenisnya. Beberapa di antaranya adalah yang bersifat naratif, posedural, hortatorik, ekspositorik, dan deskrtiptif.

1) Wacana Naratif

2) Wacana Prosedural

3) Wacana Hortatorik

4) Wacana Ekspositorik

5) Wacana Deskriptif

\section{Persyaratan Wacana}

Harjasujana dan Mulyati
persyaratan wacana antara lain:

a. Adanya topik, topik mengacu pada hal yang dibicarakan dalam wacana. Topik adalah isi sebuah wacana. Isi wacana tidak boleh keluar dari topik. Untaian kalimat membentuk suatu keutuhan. Dalam untaian kalimat itu hanya terdapat satu topik.

b. Tuturan pengungkapan topik serta jabaran-jabaran topik yang bersangkutan, wujud konkret tuturan itu adalah kalimat atau untaian kalimat yang membentuk teks bacaan. Penjabaran topik dilakukan dengan membentuk kalimat utama dan beberapa kalimat penjelas;

c. Adanya kohesi dan koherensi, kohesi dan koherensi diperlukan alam suatu wacana agar wacana menjadi runtut.
Kohesi merupakan hubungan formal atau hubungan yang tampak pada bentuk.

\section{B. Buku Teks}

\section{Pengertian Buku Teks}

Buku teks adalah buku yang dirancang untuk penggunaan di kelas. Buku yang ditulis, disusun, dan disiapkan dengan cermat oleh pakar atau ahli dalam bidang itu dan diperlengkapi dengan sarana-sarana pengajaran yang sesuai dan serasi Bacon (Tarigan dan Tarigan, 2009:12).

Textbook dijelaskan sebagai " a book giving instruction in a subject used especially in schools" (Crowther, 1995: 1234) yang dapat diterjemahkan bahwa buku teks adalah buku yang memberikan petunjuk dalam sebuah pelajaran khususnya di sekolah.

Dari berbagai pendapat ahli dapatlah disimpulkan beberapa hal sebagai berikut:

a. Buku teks itu merupakan buku pelajaran yang ditujukan bagi siswa pada jenjang pendidikan tertentu. Contohnya buku teks untuk SD, SL TP, SMA;

b. Buku teks itu selalu berkaitan dengan bidang studi tertentu, seperti buku teks bahasa Indonesia, matematika, dll;

c. Buku teks itu selalu merupakan buku standar. Pengertian standar dimaksudkan adalah baku, menjadi acuan, berkualitas. Hal ini ditetapkan oleh Panitia Nasional Penilaian Buku Pelajaran;

d. Buku teks itu biasanya disusun dan ditulis untuk jenjang pendidikan 
tertentu. Ada buku teks untuk tingkat sekolah dasar. Ada buku teks untuk sekolah lanjutan tingkat pertama;

e. Buku teks selalu ditulis untuk menunjang sesuatu program pengajaran. Ada buku teks yang menunjang pengajaran kesastraan;

f. Buku teks biasanya disusun dan ditulis oleh para pakar di bidangnya;

g. Buku teks ditulis untuk tujuan tertentu. Buku teks mengenai bahasa Indonesia ditulis dengan tujuan pengajaran tertentu di bidang bahasa Indonesia;

h. Buku teks biasa juga dilengkapi dengan sarana pengajaran, misalnya rekaman dalam pelajaran menyimak.

\section{Fungsi Buku Teks}

Peranan buku teks menurut Greene dan Petty (Tarigan, 2009:17) adalah sebagai berikut:

a. Mencerminkan suatu sudut pandangan yang tangguh dan modern mengenai pengajaran serta mendemostrasikan aplikasinya dalam bahan pengajaran yang disajikan;

b. Menyajikan suatu sumber pokok masalah atau subjectmatter yang kaya, mudah dibaca dan bervariasi, yang sesuai dengan minat dan kebutuhan para siswa, sebagai dasar bagi program program kegiatan yang disarankan dalam keterampilan ekspresional diperoleh di bawah kondisi-kondisi yang menyerupai kehidupan yang sebenarnya;

c. Menyediakan suatu sumber yang tersusun rapi dan bertahap mengenai keterampilan-keterampilan ekspresional yang membawa masalah pokok dalam komunikasi;

d. Menyajikan bersama-sama dengan buku manual yang mendampingi metode-metode dan sarana pengajaran untuk memotivasi para siswa;

e. Menyajikan fiksasi (perasaan yang mendalam) awal yang perlu dan juga sebagai penunjang bagi latihanlatihan dan tugas-tugas praktis;

f. Menyajikan bahan atau sarana evaluasi dan remedial yang serasi dan tepat guna.

\section{Kriteria dan Karakteristik Buku Teks}

Untuk menentukan berkualitas tidaknya sebuah buku teks haruslah memenuhi kriteria. Butir-butir yang harus dipenuhi oleh suatu buku teks agar dapat digolongkan berkualitas tinggi antara lain:

a. Sudut pandangan (point of view).

b. Kejelasan konsep.

c. Relevan dengan kurikulum.

d. Menarik minat.

e. Menumbuhkan motivasi.

f. Menstimulasi aktivitas siswa.

g. IIustratif.

h. Mudah dipahami.

i. Menunjang mata pelajaran lain.

j. Menghargai perbedaan individu.

\section{Telaah terhadap Masalah Keterbacaan}

\section{Sejarah keterbacaan}

Keterbacaan pertama kali dimunculkan oleh Thorndike yang 
menganggap keterbacaan adalah sebuah pendekatan. Thorndike membuat rancangan pertama tentang keterbacaan. Rancangan tersebut tersebar tetapi baru dipublikasikan setelah ada penelitian objektif tentang katakata yang dianggap sulit. Rancangan ini dikembangkan oleh Lively dan Pressey pada tahun 1923 dengan nama readability formulas. Sejak saat itulah readability lebih diperhatikan dan sering digunakan sebagai hasil penelitian yang kontroversial.

Dua faktor yang menurut para pakar termasuk faktor yang paling sering dijadikan sebagai bahan pertimbangan dalam pengukuran keterbacaan wacana berbahasa Indonesia, yaitu:

1) Panjang kalimat dan kerumitan kata

2) Perbedaan latar belakang penulis dengan pembaca

\section{Pengertian Keterbacaan}

Baca (v), membaca (v) memiliki arti 1 melihat serta memahami isi dari apa yang tertulis (dengan melisankan atau hanya dalam hati). 2 mengeja atau melafalkan apa yang tertulis, 3 mengucapkan 4 mengetahui, meramalkan 5 memperhitungkan, memahami (Alwi, dkk, 2007: 83). Berdasarkan makna leksikal kata membaca, dapat disimpulkan bahwa membaca adalah kegiatan melihat dan mengucapkan sebuah tulisan baik diikuti melisankan atau hanya dalam hati sehingga dapat memahami apa yang menjadi isi dari tulisan tersebut.

3. Faktor-faktor yang Mempengaruhi Keterbacaan suatu Teks Wacana

Harjasujana dan Mulyati

(1996:107) membuktikan bahwa ada dua faktor yang berpengaruh terhadap keterbacaan teks suatu wacana, yaitu: (1) panjang pendeknya kalimat dan (2) tingkat kesulitan kata. Pada umumnya, semakin panjang kalimat dan semakin panjang katakatanya, bacaannya semakin sukar.

\section{Hubungan Tingkat Keterbacaan dengan Siswa}

Tingkat keterbacaan sebuah buku sangat dipengaruhi oleh banyak faktor. Faktor yang memengaruhi itu, antara lain adalah tingkat kecerdasan anak didik dan cara penyajian buku itu sendiri. Hubungan antara tingkat keterbacaan dan pembaca itu terkait erat dengan keberhasilan membaca.

Putra (dalam Suladi dkk., 2000) memberikan kriteria tingkat keterbacaan sebagai berikut: (1) siswa yang mendapat nilai $>53 \%$ digolongkan sebagai siswa yang memiliki tingkat pemahaman tinggi, dapat belajar sendiri, buku tepat disajikan untuk siswa tersebut, (2) siswa dengan nilai 44$53 \%$ digolongkan sebagai tingkat pemahaman sedang, dia harus belajar di bawah bimbingan guru, (3) Siswa dengan nilai $<44 \%$ dapat bawah bimbingan guru secara intensif.

\section{Beberapa Teknik Pengukuran Tingkat Keterbacaan \\ Untuk meningkatkan} keterampilan membaca, guru dituntut untuk dapat memilah dan memilih bahan bacaan yang sesuai dengan tujuan dan tingkat perkembangan siswa, kompetensi bahasa, dan tingkat kesukaran. Pertimbangan yang menjadi dasar adalah keterbacaan. Tingkat keterbacaan harus serasi dengan tingkat kemampuan siswa. Ada beberapa formula yang dapat dipergunakan untuk mengukur tingkat keterbacaan, yaitu grafik Fry, grafik 
Raygor, dan peosedur klose.

a. Grafik Fry

b. Grafik Raygor

c. Cloze Test

Cloze Test ini diperkenalkan oleh Wilsan Taylor. Prosedur klose mempunyai dua fungsi utama, yaitu: (1) sebagai alat ukur keterbacaan dan (2) sebagai alat pengajaran membaca.

Cloze Test baku mempunyai konstruksi sebagai berikut:

1) Memilih wacana yang relatif sempurna, yang tidak bergantung pada informasi sebelumnya. Teks yang dipilih panjangnya lebih kurang 250 kata;

2) Melakukan penghilangan/pengosongan kata ke-n tanpa memperhatikan arti dan fungsi kata-kata itu. Membiarkan kalimat pertama dan terakhir utuh;

3) Mengganti bagian-bagian yang

Jumlah jawaban yang benar

$\mathrm{TK}=\frac{}{\text { Jumlah seluruh lesapan }} \times 100 \%$

(Harjasujana dan Mulyani, 1996)

Penilaian prosedur klose dilakukan dengan kriteria persentase. Angka diberikan tidak hanya pada jawaban yang persis sama. Kata atau jawaban yang dapat dihilangkan tersebut dengan tanda garis lurus datar yang sama panjangnya. Mulai menghilangkan dari kalimat kedua, yaitu pada setiap kata kelima. Jika kebetulan kata kelima jatuh pada kata bilangan, jangan dihilangkan sebagai gantinya mulai dengan hitungan kelima;

4) Memberi salinan dari semua bagian yang direproduksi kepada siswa;

5) Menggiatkan siswa untuk berusaha mengisi semua delisi dengan pertanyaan-pertanyaan dari konteks atau kata-kata sisanya;

6) Menyediakan waktu yang relatif cukup untuk memberi kesempatan kepada siswa dalam menyelesaikan tugasnya Chaniago (dalam Suladi dkk., 2000).

Setelah itu, mereka menghitung, persentase kebenaran jawaban dengan rumus yang ditetapkan,

Tabel 2. Klasifikasi tingkat baca siswa

\begin{tabular}{cc}
\hline Persentase skor tes klose & Tingkat baca \\
\hline$>60 \%$ & Independen $/$ bebas \\
$41-60 \%$ & Instruksional \\
$<40 \%$ & Frustasi \\
\hline
\end{tabular}




\section{METODE PENELITIAN}

\section{A. Variabel dan Desain Penelitian}

\section{Variabel Penelitian}

Penelitian mengamati satu variabel (variabel tunggal). Variabel tersebut adalah keterbacaan wacana buku teks pelajaran bahasa Indonesia untuk kelas VII SMP Negeri 3 Tarowang.

\section{Desain Penelitian}

Desain penelitian yang digunakan dalam penelitian ini adalah deskriptif kualitatif. Fokusnya adalah penggambaran secara menyeluruh tentang tingkat keterbacaan wacana buku teks pelajaran bahasa dan sastra Indonesia kelas VII. Hal ini sejalan dengan pendapat Bogdan dan Taylor (1975) dalam Moleong (2004: 3) yang menyatakan "metodologi kualitatif" sebagai prosedur penelitian yang menghasilkan data deskriptif berupa katakata tertulis atau lisan dari orang-orang dan perilaku yang dapat diamati.

\section{B. Definisi Operasional}

Untuk

menghindari

kesalahpahaman penafsiran penelitian ini, maka variabel yang digunakan didefinisikan secara operasional. Adapun definisi operasional variabel yang dimaksud, yaitu:

1. Tingkat keterbacaan wacana buku teks pelajaran bahasa Indonesia yang digunakan di kelas VII SMP Negeri 3 Tarowang. Tingkat keterbacaan wacana buku teks pelajaran bahasa Indonesia, yaitu tingkat kualitas isi wacana sebagai bahan ajar yang sesuai dengan tingkat pemahaman dan karakteristik setiap siswa yang berbeda sehingga dapat dipahami dengan baik.

2. Buku teks adalah buku yang dirancang untuk penggunaan di kelas.

3. Cloze Test adalah salah satu alat ukur yang digunakan untuk mengukur tingkat keterbacaan suatu wacana yaitu dengan cara mengosongkan kata-kata tertentu pada hitungan kata tertentu misalnya setiap kata kelima yang dihilangkan pada wacana.

\section{Populasi dan Sampel}

Populasi dalam penelitian ini adalah semua wacana yang memenuhi syarat untuk diuji dalam buku teks pelajaran bahasa Indonesia kelas VII SMP Negeri 3 Tarowang yang ditulis oleh Suparno dkk. dengan terbitan pertama tahun 2008 dan diterbitkan oleh Bumi Aksara, wacana yang dapat dijadikan populasi terdiri atas 11 wacana fiksi dan 9 wacana nonfiksi. Populasi yang dijadikan sampel hanya 50\% dari jumlah wacana. Jadi, jumlah wacana yang dianalisis adalah 5 wacana fiksi dan 5 wacana nonfiksi. Wacana tersebut dipilih secara acak. Wacana tersebut akan diteskan kepada siswa kelas VII SMP Negeri 3 Tarowang.

\section{D . Teknik Pengumpulan Data}

1. Teknik Observasi

2. Teknik Tes

E. Teknik Analisis Data

Wacana yang terpilih menjadi sampel dianalisis dengan dua cara yaitu: (1) 
analisis setiap wacana dan (2) analisis keseluruhan data wacana. Dari hasil analisis ditarik simpulan untuk menentukan posisi pembaca apakah di posisi tingkat baca independen/bebas, instruksional/sedang, atau frustasi/gagal.

Tabel 3. Klasifikasi Tingkat Baca

\begin{tabular}{cc}
\hline Persentase Skor Tes Klose & Tingkat Baca \\
\hline$>60 \%$ & Independen/bebas \\
$41-60 \%$ & Instruksional \\
$<40 \%$ & Frustasi \\
\hline
\end{tabular}

Interpretasi hasil klose dari Rankin (dalam Harjasujana dan Mulyani, 1996)

Wacana nonfiksi ini terdiri atas 9

\section{HASIL DAN PEMBAHASAN}

Ada beberapa faktor yang mempengaruhi tingkat keterbacaan suatu wacana, antara lain: panjang kalimat, kerumitan susunan kalimat, dan tingkat kesulitan kata.

\section{A. Penyajian Hasil Analisis Data}

\section{Deskripsi Data}

Keterbacaan wacana buku teks pelajaran bahasa Indonesia untuk kelas VII SMP Negeri 3 Tarowang dipilih 10 dari 20 wacana berupa wacana fiksi dan nonfiksi. Jadi, wacana yang dijadikan sampel dalam penelitian ini sebanyak 10 wacana yang terdiri atas 5 wacana nonfiksi dan 5 wacana fiksi. Kesepuluh wacana itu, yaitu:

1. Mengapa Kentang Goreng disebut French Fries. Wacana ini tergolong wacana nonfiksi dan terdiri atas 8 paragraf, 33 kalimat, dan 367 kata;

2. Sejumlah Daerah Diterjang Angin . paragraf, 20 kalimat, dan 259 kata;

3. Total Korban Tewas 55.175, Indonesia 27.000. Wacana ini termasuk wacana nonfiksi yang terdiri atas 5 pararaf, 23 kalimat, dan 281 kata;

4. Keberagaman dan Kebangsaan. Wacana ini tergolong nonfiksi yang terdiri atas 8 paragraf 31 kalimat, dan 452 kata;

5. Kekurangan Vitamin B12 Hambat Pertumbuhan. Wacana ini termasuk wacana nonfiksi. Ada 14 paragraf, 36 kalimat, dan 637 kata;

6. Beginikah Rasanya. Wacana ini tergolong fiksi dan terdiri atas 7 paragraf, 30 kalimat, dan 315 kata;

7. Salah Peran, termasuk wacana fiksi. Ada 8 paragraf, 35 kalimat, dan 305 pada wacana ini;

8. Lelaki Dalam Asap Mesiu. Wacana ini termasuk fiksi yang terdiri atas 7 paragraf, 33 kalimat, dan 355;

9. Jaka Tole. Wacana ini termasuk wacana fiksi dan terdiri atas 15 paragraf , 59 kalimat, dan 575 kata; 
10. Bangau Tua yang Licik. Wacana ini paragraf, 79 kalimat, dan 777 kata; tergolong fiktif yang terdiri atas 30

Tabel 4. Hasil Skor/Persentase Skor Cloze Test Wacana Nonfiksi Siswa Kelas VII SMPN 3 Tarowang

\begin{tabular}{|c|c|c|c|c|c|c|c|c|c|c|}
\hline \multirow{2}{*}{$\begin{array}{c}\text { No. } \\
\text { Urut }\end{array}$} & \multicolumn{9}{|c|}{ Wacana Nonfiksi } \\
\cline { 2 - 11 } & \multicolumn{2}{|c|}{ I } & \multicolumn{2}{|c|}{ II } & \multicolumn{2}{|c|}{ III } & \multicolumn{2}{|c|}{ IV } & \multicolumn{2}{|c|}{ V } \\
\cline { 2 - 11 } & Skor & $\%$ & Skor & $\%$ & Skor & $\%$ & Skor & $\%$ & Skor & $\%$ \\
\hline 1 & 31 & 49,2 & 25 & 58,1 & 23 & 46,9 & 40 & 48,8 & 49 & 49 \\
2 & 22 & 34,9 & 21 & 48,8 & 15 & 30,6 & 30 & 36,6 & 31 & 31 \\
3 & 19 & 30,1 & 17 & 39,5 & 19 & 38,8 & 25 & 30,5 & 27 & 27 \\
4 & 29 & 46 & 24 & 55,8 & 25 & 51 & 35 & 42,7 & 33 & 33 \\
5 & 18 & 28,6 & 17 & 39,5 & 17 & 34,7 & 38 & 46,3 & 25 & 25 \\
6 & 33 & 52,4 & 30 & 69,8 & 25 & 51 & 40 & 48,8 & 37 & 37 \\
7 & 30 & 47,6 & 23 & 53,5 & 22 & 44,9 & 20 & 24,4 & 36 & 36 \\
8 & 27 & 42,9 & 23 & 53,5 & 20 & 40,8 & 25 & 30,5 & 31 & 31 \\
9 & 21 & 33,3 & 26 & 60,5 & 14 & 28,6 & 36 & 43,9 & 27 & 27 \\
10 & 30 & 47,6 & 20 & 46,5 & 18 & 36,7 & 27 & 32,9 & 29 & 29 \\
11 & 35 & 55,6 & 30 & 69,8 & 26 & 53,1 & 39 & 47,6 & 39 & 39 \\
12 & 30 & 47,6 & 27 & 62,8 & 21 & 42,9 & 38 & 46,3 & 41 & 41 \\
13 & 25 & 39,7 & 19 & 44,2 & 17 & 34,7 & 29 & 35,4 & 29 & 29 \\
14 & 21 & 33,3 & 18 & 41,9 & 16 & 32,7 & 28 & 34,1 & 27 & 27 \\
15 & 22 & 34,9 & 16 & 37,2 & 18 & 36,7 & 30 & 36,6 & 25 & 25 \\
16 & 26 & 41,3 & 19 & 44,2 & 26 & 53,1 & 36 & 43,9 & 28 & 28 \\
17 & 25 & 39,7 & 17 & 39,5 & 19 & 38,8 & 35 & 42,7 & 34 & 34 \\
18 & 27 & 42,9 & 20 & 46,5 & 20 & 40,8 & 37 & 45,1 & 21 & 21 \\
19 & 28 & 44,4 & 24 & 55,9 & 17 & 34,7 & 29 & 35,4 & 29 & 29 \\
20 & 24 & 38,1 & 20 & 46,5 & 16 & 32,7 & 31 & 37,8 & 26 & 26 \\
\hline$\sum$ & 523 & & 436 & & 394 & & 648 & & 624 & \\
\hline
\end{tabular}

Tabel 5. Hasil Skor/Persentase Skor Cloze Test Wacana Fiksi Siswa Kelas VII SMPN 3 Tarowang

\begin{tabular}{|c|c|c|c|c|c|c|c|c|c|c|}
\hline \multirow{2}{*}{$\begin{array}{c}\text { No. } \\
\text { Urut }\end{array}$} & \multicolumn{10}{|c|}{ Wacana Fiksi } \\
\cline { 2 - 11 } & \multicolumn{2}{|c|}{ VI } & \multicolumn{2}{|c|}{ VII } & \multicolumn{2}{c|}{ VIII } & \multicolumn{2}{|c|}{ IX } & \multicolumn{2}{|c|}{ X } \\
\cline { 2 - 10 } & Skor & $\%$ & Skor & $\%$ & Skor & $\%$ & Skor & $\%$ & Skor & $\%$ \\
\hline 1 & 29 & 51,8 & 24 & 43,6 & 23 & 41,1 & 41 & 51,3 & 62 & 62 \\
2 & 21 & 37,5 & 21 & 38,2 & 17 & 30,4 & 30 & 37,5 & 49 & 49 \\
3 & 27 & 48,2 & 26 & 47,3 & 19 & 33,9 & 46 & 57,5 & 35 & 35 \\
4 & 25 & 44,6 & 24 & 43,6 & 21 & 37,5 & 42 & 52,5 & 33 & 33 \\
5 & 21 & 37,5 & 17 & 30,9 & 18 & 32,1 & 38 & 47,5 & 61 & 61
\end{tabular}




\begin{tabular}{|c|c|c|c|c|c|c|c|c|c|c|}
6 & 28 & 50 & 25 & 45,5 & 26 & 46,4 & 45 & 56,3 & 47 & 47 \\
7 & 26 & 46,4 & 23 & 41,8 & 23 & 41,1 & 43 & 53,8 & 41 & 41 \\
8 & 27 & 48,2 & 24 & 43,6 & 20 & 35,7 & 41 & 51,3 & 60 & 60 \\
9 & 29 & 51,8 & 26 & 47,3 & 18 & 32,1 & 51 & 63,8 & 59 & 59 \\
10 & 24 & 42,9 & 20 & 36,4 & 18 & 32,1 & 45 & 56,3 & 36 & 36 \\
11 & 29 & 51,8 & 26 & 47,3 & 24 & 42,9 & 50 & 62,5 & 39 & 39 \\
12 & 21 & 37,5 & 27 & 49,1 & 21 & 37,5 & 40 & 50 & 54 & 54 \\
13 & 23 & 41,1 & 23 & 41,8 & 19 & 33,9 & 40 & 50 & 55 & 55 \\
14 & 19 & 33,9 & 18 & 32,7 & 16 & 28,6 & 49 & 61,3 & 40 & 40 \\
15 & 17 & 30,4 & 16 & 29,1 & 18 & 32,1 & 41 & 51,3 & 50 & 50 \\
16 & 18 & 32,1 & 19 & 34,5 & 20 & 35,7 & 43 & 53,8 & 36 & 36 \\
17 & 27 & 48,2 & 17 & 30,9 & 24 & 42,9 & 41 & 51,3 & 50 & 50 \\
18 & 27 & 48,2 & 20 & 36,4 & 20 & 35,7 & 43 & 53,8 & 53 & 53 \\
19 & 19 & 33,9 & 24 & 43,6 & 17 & 30,4 & 35 & 43,8 & 37 & 37 \\
20 & 17 & 30,4 & 20 & 36,4 & 19 & 33,9 & 47 & 58,8 & 45 & 45 \\
\hline$\sum$ & 474 & & 440 & & 401 & & 851 & & 942 & \\
\hline
\end{tabular}

\section{B. Pembahasan Hasil Penelitian}

Beberapa Temuan yang Mempengaruhi Tingkat Keterbacaan Wacana

\section{1) Panjang Kalimat}

Wacana IV memiliki kalimat yang panjang. Kalimat yang panjang akan menyulitkan siswa dalam memahaminya. Seperti pada paragraf ketiga "Belum lagi munculnya perasaan dan sentimen etnik sebagai "penguasa" suatu wilayah merasa dipinggirkan secara ekonomi dan tidak mendapat posisi yang layak secara politis". Selain itu, kalimat panjang terdapat pula pada paragraf keenam "Saat menjalani masa pembuangan di Banda Neira (1936), Sjahrir melihat nasionalisme untuk merdeka tidak berdasarkan pada fanatisme agama, tetapi lebih bersifat politis dan ekonomi."

Kalimat-kalimat yang panjang tidak hanya terdapat dalam wacana IV tetapi juga terdapat pada wacana $\mathrm{V}$ paragraf ketiga "Hal ini karena vitamin B12 hanya dapat ditemukan dalam produk hewan dan jarang terdapat pada makanan nabati, kecuali kalau bahan itu berasal dari rumput laut atau yang terkontaminasi oleh feses." Selain itu, pada wacana VIII terdapat paragraf yang hanya memiliki satu kalimat, yaitu paragraf pertama " Tatkala suara ledakan menggelegar keras, beton dan kacakaca jendela rontok seperti daun di musim gugur, Achmad Usman, 39 tahun, berlari menyongsong asap putih yang merupakan bau mesiu di depan Kedutaan Besar Australia, Jalan Rasuna Said, Jakarta Selatan, Kamis 9 September lalu". Kalimat ini dapat dijadikan dua kalimat.

\section{2) Susunan Kalimat}

Susunan kalimat-kalimat yang terlalu rumit jelas terlihat pada wacana nonfiksi. Sebuah teks yang terlalu rumit 
akan sulit untuk dimaknai. Memadukan antara kalimat langsung dan tak langsung dalam wacana fiksi menjadi salah satu penyebab rendahnya tingkat keterbacaan wacana fiksi. Penguasaan siswa yang rendah terhadap kalimat langsung dan kalimat tak langsung menjadi kesulitan tersendiri.

\section{3) Kesulitan Kata}

Beberapa wacana yang dijadikan sampel dalam penelitian ini mempunyai tingkat kesulitan kata yang bervariasi. Dalam wacana I istilah asing yang sering dipakai penulis dalam teks yaitu "fast food, french fries, freedom fries, junk food, dan trend. Pada wacana $\mathrm{V}$ juga terdapat istilahistilah kedokteran seperti "kobalamin, feses, spirulina, vegetarian, selenium, anemia, koenzim, mielin, sintesis DNA, delusi, dan devisiensi". Banyaknya kata dan istilah baru menyebabkan siswa sulit untuk memahami apa maksud wacana tersebut.

Dalam wacana ini ada pula istilah yang dipakai penulis yang tidak asing di telinga siswa karena istilah tersebut dikategorikan bahasa gaul seperti kata "notabene, pede, nggak ketulungan, dan nongol.

Wacana IX dengan judul Jaka Tole adalah wacana yang tingkat keterbacaannya paling tinggi diantara wacana-wacana yang lain. Wacana tersebut paling sering mereka dapatkan dan sudah sering dibaca oleh siswa. Minat dan perhatian yang tinggi terhadap bacaan tertentu, dapat dipastikan akan memperoleh pemahaman yang lebih baik terhadap topik tersebut dibandingkan jika kurang atau tidak berminat terhadap topik tersebut. Hal ini terlihat jelas pada wacana IX. Siswa dapat mengisi jawaban kosong karena materi dalam wacana tersebut sangat dekat dengan mereka. Mereka mengenal dan hampir menghapal setiap kata dalam wacana itu. Jaka Tole adalah salah satu cerita rakyat yang sering ditemukan oleh siswa dalam buku kumpulan cerita rakyat. Buku semacam ini sering ditemukan di perpustakaan sekolah sebagai sumber bacaan anak sekolah di waktu istirahat.

Penulis dapat simpulkan bahwa dari kesepuluh wacana yang dijadikan sampel, ada 7 (tujuh) wacana yang layak dijadikan bahan ajar untuk kelas VII. Wacana tersebut adalah wacana I, II, III,VI, VII, IX, dan X. Tiga wacana lainnya tidak dapat dijadikan sebagai bahan ajar untuk kelas VII. Dari lima sampel wacana fiksi hanya satu yang tidak layak dijadikan bahan ajar yaitu wacana VIII dengan judul Lelaki Dalam Asap Mesiu. Wacana VIII itu merupakan kutipan dari koran. Sedangkan koran adalah bahan bacaan untuk umum yang tidak dirancang sebagai bahan ajar.

\section{SIMPULAN DAN SARAN}

\section{A. Simpulan}

Berdasarkan analisis dan pembahasan hasil penelitian, dapat disimpulkan penelitian ini sebagai berikut:

1. Tingkat keterbacaan wacana I, II, III, VI, VII, IX dan X dapat dijadikan bahan ajar untuk siswa kelas VII SMP Negeri 3 Tarowang. Wacana tersebut berada pada tingkat baca instruksional yang menandakan wacana tersebut memiliki tingkat kesulitan sedang dan sesuai dengan tingkat pemahaman siswa. Selanjutnya, tingkat keterbacaan wacana IV, V, dan VIII tidak layak bagi siswa kelas VII SMP Negeri 3 
Tarowang. Wacana ini menempatkan responden pada tingkat baca frustasi. Dengan demikian, dapat dinyatakan bahwa tingkat keterbacaan wacana buku teks pelajaran bahasa Indonesia untuk kelas VII SMP Negeri 3 Tarowang berada pada tingkat sedang, yaitu berada pada tingkat baca instruksional. Hal ini menandakan tingkat keterbacaan wacana secara keseluruhan dapat dipahami siswa.

2. Berdasarkan Tabel pembahasan Frekuensi Kemunculan Responden pada Kategori Tingkat Baca Wacana Nonfiksi Yaitu responden yang memiliki tingkat baca independen hanya 4 orang atau 4\% dari 100 responden lebih sedikit dari wacana fiksi. Responden yang memiliki tingkat baca instruksional hampir sama banyak dan responden berada pada tingkat baca frustasi lebih banyak pada wacana nonfiksi. Hal ini disebabkan karena sebagian besar wacana nonfiksi baru dibacanya.

3. Pada umumnya tingkat keterbacaan wacana dipengaruhi oleh panjang kalimat, susunan kalimat yang rumit, dan kesulitan kata.

\section{B. Saran}

Berdasarkan simpulan hasil temuan dalam penelitian ini, maka penulis menyarankan kepada pihak yang terkait langsung dengan penelitian ini, sebagai berikut:

1. Guru bahasa Indonesia: sebelum memilih suatu wacana yang akan dijadikan sebagai bahan ajar, hendaknya wacana tersebut diukur terlebih dahulu tingkat keterbacaannya agar siswa cepat menerima dan memahami materinya.

2. Pihak sekolah: sebaiknya dimusyawarahkan terlebih dahulu dengan guru bidang studi mengenai tingkat keterbacaan wacana yang ada dalam buku teks tersebut.

3. Penerbit: haruslah diukur terlebih dahulu tingkat keterbacaan wacana yang akan dimasukkan ke dalam buku teks agar mudah dipahami oleh siswa.

\section{DAFTAR PUSTAKA}

Alwasilah, Chaedar. 2007. Menaksir Buku Ajar. Online (http://www.yahoo.com/piki ran rakyat). Diakses 15 Januari 2013.

Alwi, Hasan., dkk (eds.). 1998. Tata Bahasa Baku Bahasa Indonesia. Jakarta: Balai Pustaka.

Alwi, Hasan, dkk (eds). 2007. Kamus Besar Bahasa Indonesia Edisi III Cetakan IV.Jakarta: Balai Pustaka.

Arikunto, Suharsimi. 2003. Manajemen Penelitian. Jakarta: Rineka Cipta.

Baradja, M.F. 1991. Kapita Selekta Pengajaran Bahasa. Malang: IKIP Malang.

Darma, Yoce Aliyah. 2009. Analisis Wacana Kritis. Bandung: Irama Wijaya

Husen H, Akhlan dkk. 1998. Telaah Kurikulum dan Buku Teks Bahasa Indonesia. Jakarta: Depdikbud Dirjen Dikdasmen Bagian proyek 
Penataran Guru SL TP

Setara D. III.

Klare, George R. 1984. Handbook of

Reading Research:

Readability. London:

Longman.

Moleong, Lexy J. 2004. Metodologi

Penelitian Kualitatif.

Bandung: Remaja Rosda

Karya.

Oller, John W. 1979. Language Tests at

School. London: Longman

Palmer, F.R. 1992. Semantik. Terj. Abdullah

Hasan. Kuala Lumpur:

Printsystem Sdn. Bhd.

Putrayasa, Ida Bagus. 2006. Analisis

Kalimat. Bali: Refika

Aditama.

Saemina. 2005. Tingkat Keterbacaan

Wacana Buku Teks

Pelajaran Bahasa dan Sastra

Indonesia untuk Kelas VII

Sekolah Menengah pertama.

Tesis tidak diterbitkan.

Makassar: PPs UNM.

Suparno, dkk. 2008. Bahasa dan Sastra

Indonesia 1 SMP/MTs.

Jakarta: Bumi Aksara.

Tarigan, Henry Guntur. 2009. Telaah Buku

Teks Bahasa Indonesia.

Bandung: Angkasa. 